LETTER TO EDITOR

\title{
Acute Pulmonary Embolism in Dual Dengue Fever and Influenza B Infection
}

\author{
Wen Chi Hsu' and Wen Liang $\mathrm{Yu}^{2,3 *}$ \\ ${ }^{1}$ Department of Nursing, Chi Mei Medical Center, Tainan, Taiwan \\ ${ }^{2}$ Department of Intensive Care Medicine, Chi Mei Medical Center, Tainan, Taiwan \\ ${ }^{3}$ Department of Medicine, Taipei Medical University, Taipei, Taiwan
}

*Corresponding author: Wen-Liang Yu, Department of Intensive Care Medicine, Chi Mei Medical Center, No. 901 Chunghwa Road, Yongkang District, Tainan City, 710, Taiwan, Tel: +886-6-2812811, Fax: +886-6-2833351, E-mail: Yuleon_md@yahoo.com.tw

\section{Keywords \\ Dengue, Influenza B, Pulmonary embolism}

\section{Letter}

\section{Dear Editor,}

Acute Pulmonary Embolism (PE) is a life-threatening condition and the common cause of death is due to obstruction of main pulmonary vessels by the embolus, resulting in pulmonary hypertension followed by right-sided heart failure [1]. Acute PE often occurs in some patients with hereditary and acquired factors predisposing them at a risk for the development of thrombotic events. The hereditary hypercoagulable state due to genetic mutations, such as deficiency of protein $C$ and protein $S$, involves an increased risk of recurrent venous thromboembolism [2]. The acquired risk factors are commonly seen in some inflammatory or infectious diseases, such as influenza [3], whereas dengue fever has been rarely described [4]. Herein, we describe a diabetic patient with dual dengue fever and influenza $B$ infection, who developed an isolated subsegmental pulmonary embolism.

A 71-year-old diabetic woman with hypertension history suffered from the dizziness, fever, and general weakness on September 13, 2015 during a large dengue outbreak in Tainan city, Taiwan [5]. She was sent to the emergency room of the hospital. The serum dengue virus Nonstructural protein 1 (NS1) antigen showed a positive result, while anti-dengue IgM and anti-dengue IgG antibodies were negative. The presenting serum data included platelet count, 177,000/ $\mu \mathrm{L}$; Asparatate Transaminase (AST), $46 \mathrm{U} / \mathrm{L}$; and Alanine Aminotransferase (ALT), $43 \mathrm{U} / \mathrm{L}$. The Computed Tomography (CT) scan of the brain did not indicate obvious lesion except mild brain atrophy. Under the impression of dengue fever, she was admitted to the ward for further management.

A platelet count dropped to the lowest level of $11,000 / \mu \mathrm{L}$ on September 16. After five days of hospitalization, however, she felt worsening malaise, dizziness, anorexia, and newly developed dyspnea. The abnormal serum laboratory data included platelet count 20,000/ $\mu \mathrm{L} ; \mathrm{AST}, 1704 \mathrm{U} / \mathrm{L} ; \mathrm{ALT}, 762 \mathrm{U} / \mathrm{L}$; total bilirubin, 3.24 $\mathrm{mg} / \mathrm{dL}$, direct bilirubin, $1.84 \mathrm{mg} / \mathrm{dL}$, albumin, $2.9 \mathrm{~g} / \mathrm{dL}$; lactate $(4.1 \mathrm{mmol} / \mathrm{L}), \mathrm{D}$-dimer $(3271 \mathrm{ng} / \mathrm{mL}$, normal < $500)$ and activated partial thromboplastin time, 51.5 seconds. Hypoxemia was noted with an arterial Oxygen Partial Pressure $\left(\mathrm{PaO}_{2}\right)$ of $57.2 \mathrm{mmHg}$ with using the Fractional Inspired Oxygen $\left(\mathrm{FiO}_{2}\right)$ of $35 \%\left(\mathrm{PaO}_{2} / \mathrm{FiO}_{2}\right.$, $163.4 \mathrm{mmHg}$ ). The chest $X$-ray revealed mild infiltration over bilateral lung fields, suggesting pulmonary edema. The chest CT scan revealed partial thrombosis of right pulmonary artery at superior lobar branch (Figure 1).

Therefore, she was admitted to the intensive care unit. In addition, the result of rapid influenza diagnostic test revealed positive for influenza $B$ antigen in nasopharyngeal swab. The throat Polymerase Chain Reaction (PCR) for Influenza A (H1N1), H3N2 and influenza A were all negative. The dengue virus-PCR as well as anti-dengue IgM and anti-dengue IgG antibodies in serum were all positive on the $8^{\text {th }}$ hospitalized day. A 5-day course of oseltamivir and

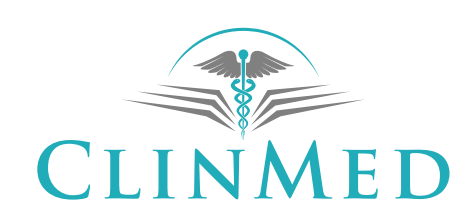

INTERNATIONAL LIBRARY
Citation: Hsu WC, Yu WL (2017) Acute Pulmonary Embolism in Dual Dengue Fever and Influenza B Infection. Int J Virol AIDS 3:033. doi.org/10.23937/2469-567X/1510033

Received: August 01, 2017: Accepted: September 06, 2017: Published: September 08, 2017

Copyright: (C) 2017 Hsu WC, et al. This is an open-access article distributed under the terms of the Creative Commons Attribution License, which permits unrestricted use, distribution, and reproduction in any medium, provided the original author and source are credited. 

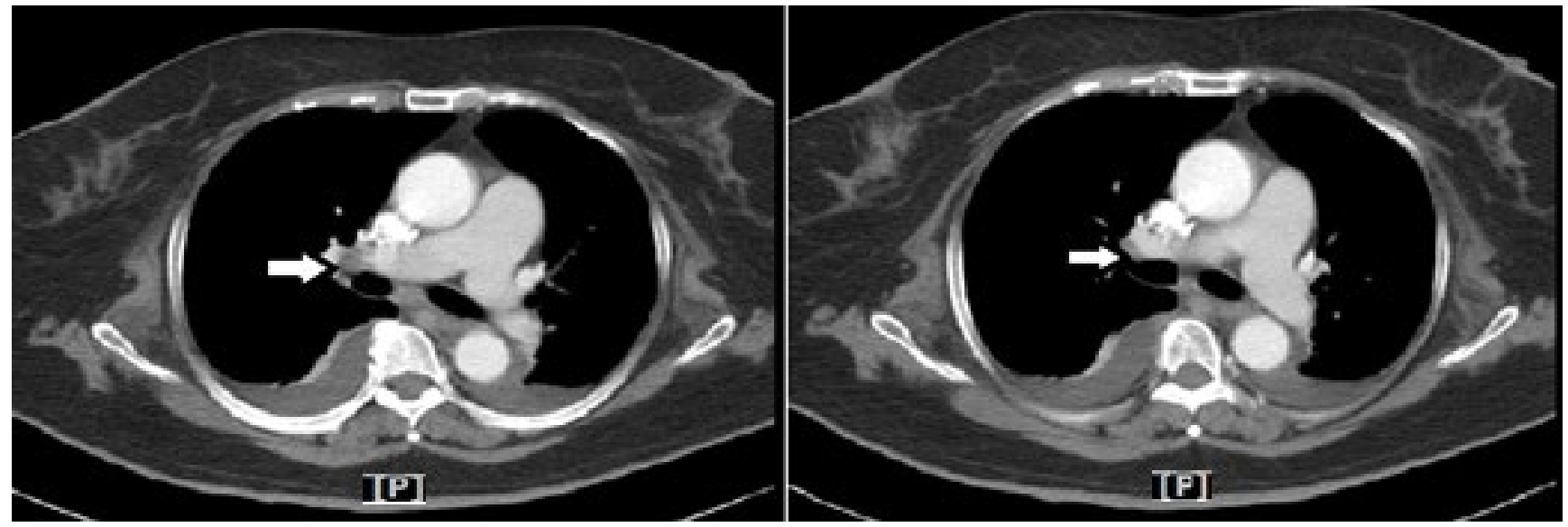

Figure 1: The chest CT is showing partial thrombosis of right pulmonary artery at superior lobar branch (arrow).

antibiotic therapy with levofloxacin were given. Then fever subsided and dyspnea was improved. The blood protein C activity was $51.3 \%$ (normal, $70-140 \%$ ) and the protein S activity was $55.3 \%$ (normal, $60-130 \%$ ). Follow-up platelet count and liver function tests became normal, so she was transfer to ward. Following heparin therapy, warfarin treatment was titrated to daily $2.5 \mathrm{mg}$ to achieve the desired prothrombin time ratio. She was uneventfully discharged after 16 days of hospitalization.

Pulmonary embolism has been reported in association with dengue fever or severe influenza, particularly Influenza $A(H 1 N 1)[3,4]$. Coexistence of severe dengue, influenza $B$ and acute pulmonary embolism in a single patient was not reported before. The underlying risk factors for increased thrombophilia activity of our patient were relatively lower plasma concentrations of proteins $\mathrm{C}$ and $\mathrm{S}$. $\mathrm{Pa}$ tients with protein $C$ levels less than $50 \%$ are likely to have a true hereditary deficiency, whereas levels between $55 \%$ and $65 \%$ such as in our patient may reflect heterozygous deficiency or the low end of the normal distribution [6]. Patients with protein $\mathrm{S}$ deficiency generally have activity levels less than $60 \%$ of normal activity [7]. Our patient with mild deficiency of proteins $\mathrm{C}$ ad $\mathrm{S}$ might not be detectably associated with a risk of thrombosis, but which could be provoked by dual severe dengue fever and influenza infection. In this patient, several risk factors other than low plasma concentration of protein $\mathrm{C}$ and $\mathrm{S}$, such as hypertension, diabetes, age over 70 and obesity (height: $160 \mathrm{~cm}$, weight: $93.6 \mathrm{Kg}$, body mass index: 36.6$)$ could probably contribute to pulmonary embolism $[8,9]$. Therefore, we could not exclude a possibility of anecdotal evidence for $P E$ in the context of dengue fever and influenza B infection. Otherwise, there were no lifestyle risk factors for PE in this patient, such as smoking, drugs, surgery and immobilization [10].

In conclusion, Acute PE could occur in the patients with influenza and/or dengue, either alone or coinfection, particularly in those patients with increased procoagulant activity, such as proteins $C$ and $S$ deficiency or in those with other risk factors of PE. Awareness for the vascular thrombotic complications should be recommended to all practitioners who treat patients with dengue fever, particularly coinfected with influenza.

\section{Conflict of Interests}

We declare no conflict of interest and financial support regarding this letter.

\section{Ethics Statement}

The case study in this work was approved by the Institutional Review Board (IRB) of Chi Mei Medical Center (IRB no. 10503-005).

\section{References}

1. Gårdlund B (1985) Fatal pulmonary embolism in hospitalized non-surgical patients. Journal of Internal Medicine 218: 417-421.

2. Heit JA (2012) Predicting the risk of venous thromboembolism recurrence. Am J Hematol 87: S63-S67.

3. Dimakakos E, Grapsa D, Vathiotis I, Papaspiliou A, Panagiotarakou M, et al. (2016) H1N1-induced venous thromboembolic events? Results of a single-institution case series. Open Forum Infect Dis 3: 214.

4. Ghatak T, Singh RK, Baronia AK (2013) Spontaneous central vein thrombosis in a patient with activated protein $\mathrm{C}$ resistance and dengue infection: An association or causation? J Anaesthesiol Clin Pharmacol 29: 547-549.

5. Chen CM, Chan KS, Yu WL, Cheng KC, Chao HC, et al. (2016) The outcomes of patients with severe dengue admitted to intensive care units. Medicine (Baltimore) 95: e4376.

6. Miletich J, Sherman L, Broze G Jr (1987) Absence of thrombosis in subjects with heterozygous protein $\mathrm{C}$ deficiency. $\mathrm{N}$ Engl J Med 317: 991-996.

7. Duebgen S, Kauke T, Marschall C, Giebl A, Lison S, et al. (2012) Genotype and laboratory and clinical phenotypesof protein S deficiency. Am J Clin Pathol 137: 178-184.

8. Cohen AT, Gitt AK, Bauersachs R, Fronk EM, Laeis P, et al. (2017) The management of acute venous thromboembolism in clinical practice. Results from the European PREFER in VTE Registry. Thromb Haemost 117: 1326-1337.

9. de Miguel-Díez J, Muñoz-Rivas N, Jiménez-García R, Hernández-Barrera V, Carrasco-Garrido, et al. (2016) Type 2 diabetes is associated with a higher incidence of hospitalization for pulmonary embolism in Spain: Analysis of hospital discharge data during 2004-2013. Respirology 21: 1277-1284.

10. Engbers MJ, Blom JW, Cushman M, Rosendaal FR, van Hylckama Vlieg A (2017) Functional impairment and risk of venous thrombosis in older adults. J Am Geriatr Soc. 